\title{
Complejos vitamina E- $\beta$-lactoglobulina incluidos en películas biopoliméricas de alginato de sodio
}

\author{
Vitamin E- $\beta$-lactoglobulin complexes included \\ in sodium alginate biopolymeric films
}

Berino, Romina, P. (2); Pezzelatto, Diego A. F. (2); Báez, Germán, D. (1, 2); Llopart, Emilce E. (1); Ballerini, Griselda, A. (2, 3); Moro, Andrea (2); Delorenzi, Néstor, J. (2); Busti, Pablo, A. (2).

(1) Facultad de Ciencias Bioquímicas y Farmacéuticas, Universidad Nacional de Rosario, Rosario, Argentina.

(2) Área Tecnología de los Alimentos, Departamento de Tecnología, Facultad de Ciencias Bioquímicas y Farmacéuticas, Universidad Nacional de Rosario, Rosario, Argentina.

(3) Centro de Investigaciones y Desarrollo en Tecnología de los Alimentos, Universidad Tecnológica Nacional, Facultad Regional Rosario, Rosario, Argentina.

Contacto: pbusti@fbioyf.unr.edu.ar

RECIBIDO: 22/3/2018 APROBADO: 22/6/2018

\begin{abstract}
Resumen
Se optimizaron las condiciones para la preparación de películas biopoliméricas capaces de encapsular los valores diarios máximos recomendados de la vitamina liposoluble $\mathrm{E}(\alpha-\mathrm{tc})$, incorporando nanocomplejos formados por la proteína láctea beta lactoglobulina $(\beta-\lg )$ y la vitamina en soluciones alginato de sodio (AS), a una relación $\beta$-lg/AS determinada previamente. En primer término, se estudió por turbidimetría la interacción entre $\beta$-lg (nativa y desnaturalizada por calor) con $\alpha$-tc, a diferentes $\mathrm{pHs}$, y se comprobó la eficacia de $\beta$-lg nativa a pH 6,80 para solubilizar la $\alpha$-tc en soluciones acuosas. Se realizaron ensayos de opacidad y color de las películas y no se encontraron diferencias por la incorporación del $\alpha$-tc. Se evaluó por HPLC la integridad de la estructura de $\alpha$-tc en los nanocomplejos formados en soluciones acuosas y en las películas de alginato a lo largo de un período de tiempo. La película seca mejoró la protección de la estructura del $\alpha$-tc al ser expuesta al oxígeno del aire y luz controlada, efecto atribuible a la barrera al oxígeno y luz ultravioleta (UV) que ofrecen las películas secas de polisacáridos.

Palabras clave: Beta lactoglobulina, nano complejos, películas, alginato de sodio.
\end{abstract}

\begin{abstract}
In order to obtain dried films capable of encapsulating the maximum recommended daily values of fat-soluble vitamin $\mathrm{E}(\alpha-\mathrm{tc})$, nanocomplexes between beta-lactoglobulin $(\beta-\mathrm{lg})$, the major whey protein, and the vitamin were incorporated into sodium alginate (AS) solutions, to previously determined $\beta-\lg /$ AS ratio. The interaction between native and heat-treated protein with vitamin was studied by turbidimetry at different $\mathrm{pH}$ values. Native $\beta$-lg increased solubility $\alpha$-tc in aqueous solutions at $\mathrm{pH}$ 6.80. Opacity and color tests to all films were carried out and no differences were found due to the incorporation of $\alpha$-tc. Dry films improved the protection of $\alpha$-tc structure when exposed to oxygen from the air and controlled light (measured by HPLC). This effect was attributable to the oxygen and ultraviolet light (UV) barrier exerted by the polysaccharide matrix.

Keywords: Beta lactoglobulin, Nanocomplexes, films, sodium alginate.
\end{abstract}

\section{Introducción}

Algunos desafíos de la industria alimentaria son: prolongar la vida útil de los alimentos, lograr incorporar en el alimento nutrientes o sustancias bioactivas y controlar su posterior liberación en sitios específicos del organismo (Tavares, et al., 2014). Los complejos formados por la interacción de proteínas con polisacáridos, como pectina o alginato, son capaces de incorporar vitaminas (Jones, et al., 2009; Zimet y Livney, 2009; Ron, et al., 2010; Fioramonti, et al., 2014). Así, el estudio y caracterización de la interacción de vitaminas hidrofóbicas con proteínas como la $\beta$-lg y su posterior incorporación en matrices biopoliméricas sólidas de alginato formaría un sistema capaz de proteger la estructura de la vitamina por un período de tiempo razonable y, a su vez, brindaría importante información sobre un modo de incorporación, en un futuro, de vitaminas a alimentos.

La $\beta$-lg es la proteína mayoritaria del lactosuero. Ha sido ampliamente estudiada por su capacidad de ligar compuestos hidrofóbicos y anfifílicos como saborizantes, vitaminas, ácidos grasos y polifenoles (Livney, 2010). En su estado nativo 
presenta diferentes sitios capaces de fijar ligandos hidrofóbicos (ácidos grasos, vitaminas liposolubles), al tiempo que, bajo determinadas condiciones, es capaz de autoensamblarse para formar superestructuras oligoméricas (Báez, et al., 2011) que permiten la encapsulación y el transporte de una diversidad de pequeñas moléculas (Livney, 2010) como $\alpha$-tocoferol (Relkin y Shukat, 2012), aromatizantes (Giroux y Britten, 2011), entre otros. La exposición de mayor número de sitios hidrofóbicos se relaciona con su grado de desnaturalización (Busti, et al., 2000; Moro, et al., 2001; Delorenzi, 2005).

El calentamiento a temperaturas superiores a $80^{\circ} \mathrm{C}$ provoca cambios en la estructura secundaria y terciaria de la proteína, ocasionando la pérdida de la cavidad interna aunque conserva parte de su actividad encapsulante. Esto último sugiere que se crean nuevos sitios de unión tras exponer al solvente otros residuos hidrofóbicos (Mousavi, et al., 2008).

La interacción de la proteína con vitaminas hidrofóbicas para incorporarlas en alimentos ha sido estudiada por otros autores (Liang, et al., 2011; Liang y Subirade, 2012; Relkin, et al., 2012; Relkin, et al., 2014), quienes analizaron las características de la fijación, la influencia de las condiciones del medio y la estabilidad de los complejos.

La vitamina E pertenece a una familia de compuestos poliprenoides. En su estado natural presenta ocho isómeros, de los cuales el $\alpha$-tc es el más abundante, biodisponible y ópticamente activo. Dentro de la amplia variedad de beneficios que aporta su ingesta, se destaca su poder antioxidante, que previene la propagación de radicales libres cuyo rol es fundamental en enfermedades crónicas y cardiovasculares. Se acepta que $20 \mathrm{mg}$ /día sería el máximo valor de ingesta que podría ser administrado como suplemento (National Institute of Health, 2016). En los suplementos dietarios, el $\alpha$-tc se encuentra como acetato y succinato de $\alpha$-Tocoferol. Bajo estas formas aumenta su estabilidad, pero se reduce, aproximadamente al 30\%, su absorción a nivel del intestino humano en comparación con la administración del $\alpha$-tc en forma pura. Esta última opción es prácticamente inviable a causa de su hidrofobicidad y alta sensibilidad al calor, al oxígeno y a la luz.

La unión del $\alpha$-tc con la $\beta$-lg produce, en el medio, distintas especies: monómeros de vitaminas hidrófobas, moléculas autoasociadas de vitaminas (nanopartículas) y complejos de proteínas y vitaminas (Liang, et al., 2011). Los complejos formados son estructuras capaces de solubilizar la vitamina en soluciones acuosas estables e incrementar su vida media, protegiéndola de factores adversos como la luz, el oxígeno y la temperatura. El enriquecimiento de alimentos con sustancias nutricionales hidrofóbicas presenta un especial desafío, debido a la dificultad de incorporar estos compuestos a sistemas acuosos. El vehículo ideal para este fin debe ser de origen natural, económico y capaz de solubilizar y proteger al bioactivo.

Los alginatos son una familia de polisacáridos binarios lineales cuya estructura consta de " $m$ " uniones $(1 \rightarrow 4)$ $\beta$-D-manurónico y " $n$ ” ácido a-l-Gulurónico. Este polímero debe su carácter polianiónico a los grupos carboxilo (pKa $=3,5$ ) que aparecen a lo largo de la cadena. La composición y extensión de las secuencias manurónico/gulurónico y el peso molecular determinan las propiedades físicas de los alginatos (Romero, et al., 2013).

La forma en la que interaccionan los alginatos y la $\beta-\lg$ varía de acuerdo al $\mathrm{pH}$ del medio en que se encuentren. A $\mathrm{pH}$ neutro, tanto el polisacárido como la proteína presentan carga negativa y ambos permanecen solubles en medio acuoso. Cerca del punto isoeléctrico de la proteína ( $\mathrm{pH} 4,7$ - 5,2) se forman complejos solubles sobre la base de interacciones electrostáticas y, a $\mathrm{pH}$ inferior a 4,7 las interacciones se ven notablemente incrementadas dando lugar a la agregación de partículas (de Kruif, et al., 2004; Qomarudin, et al., 2015).

En la actualidad se busca incorporar los beneficios provistos por los alginatos en los micro encapsulados para protegerlos de factores adversos como el oxígeno, el calor, la humedad (Ron, et al., 2010) o la radiación UV (Draget, 2009; Rhim, 2004; Pereira, et al., 2013).

\section{Materiales y métodos}

\section{Reactivos}

Se prepararon soluciones reguladoras de fosfato de sodio $(\mathrm{Pi})$ $20 \mathrm{mM}$ de pH 3,00 y 6,80 y los reactivos utilizados fueron de grado analítico. Se utilizó $\beta$-lg Sigma Chemicals Co. (St. Louis, MO, USA) de origen bovino. Las soluciones se prepararon disolviendo, sin ningún otro tipo de purificación, $25 \mathrm{mg}$ de la droga por pesado directo en $1 \mathrm{~mL}$ de las soluciones reguladoras, a ambos pHs, y conservadas a $-20^{\circ} \mathrm{C}$ hasta su utilización. Se preparó una solución madre $10 \mathrm{mM}, \alpha$-Tocoferol Sigma Chemicals Co. (St. Louis, MO, USA) en etanol absoluto Cicarelli (Rosario, Argentina) y se la mantuvo conservada en frasco color caramelo en atmósfera de nitrógeno y al abrigo de la luz. Se elaboraron soluciones madre $2 \%$ peso en volumen ( $\% \mathrm{p} / \mathrm{V})$ de AS Sigma Chemicals Co. (St. Louis, MO, USA) PM: 100.000 de viscosidad media, disolviendo $4 \mathrm{~g}$ por pesado directo de la droga sólida en $200 \mathrm{~mL}$ de las soluciones reguladoras de $\mathrm{pH}$ 3,00 y 6,80 . Las soluciones obtenidas se calentaron por 5 minutos a $60^{\circ} \mathrm{C}$ y se eliminaron los gases por aplicación de vacío.

\section{Desnaturalización por tratamiento térmico de la $\beta$-lg}

Soluciones de $\beta$-lg $20 \mu \mathrm{M}$ en buffer Pi $20 \mathrm{mM}$ pH 3,00 y pH 6,80 se calentaron a $85^{\circ} \mathrm{C}$ durante 5 minutos en baño termostático. Concluido el procedimiento, las muestras fueron llevadas a temperatura ambiente y congeladas a $-20{ }^{\circ} \mathrm{C}$.

\section{Turbidimetría}

La turbidez se determinó por medio de medidas de absorbancia (Abs) a $500 \mathrm{~nm}$ en un espectrofotómetro Jasco V-500 (Jasco International Co., Ltd., Tokyo Japan). Cada una de las muestras fue medida por triplicado. Para transformar los valores de absorbancia en turbidez, se utilizó la ecuación:

$\tau=2,303 . \mathrm{Abs}_{500 \mathrm{~nm}}$

\section{Interacción de la $\beta$-lg con $\alpha$-tc}

\section{Medidas de la turbidez de la $a$-tc}

Se midieron las turbideces iniciales de soluciones de $\beta-\lg 20 \mu \mathrm{M}$ pH 3,00 y 6,80, a las que se le fueron agregando alícuotas de una solución madre de $\alpha$-tc $10 \mathrm{mM}$, en un rango de 0 - $500 \mu \mathrm{M}$, a $25^{\circ} \mathrm{C}$. Se realizaron los blancos de proteína correspondientes para cada $\mathrm{pH}$. De igual manera se trabajó con la $\beta$ - $\lg 20 \mu \mathrm{M}$ a pH 3,00 y 6,80 desnaturalizadas por calor. La solución de $\beta$-lg a pH 3,00 gelificó y fue descartada. Para cada tipo de muestra las medidas se realizaron por triplicado. 
Obtención de películas de AS $\beta$-lg / $\alpha$-tc

Películas de AS $\sim \beta$-lg y AS $\sim \beta$-lg / $\alpha$-tc

Se prepararon películas con distintas relaciones proteína-alginato. $5 \mathrm{~mL}$ de solución de AS $2 \%$ p/V en buffer Pi $20 \mathrm{mM}$ $\mathrm{pH} 6,80$ se mezclaron con $5 \mathrm{~mL}$ de soluciones formadas por buffer Pi $20 \mathrm{mM}$ pH 6,80 y distintas cantidades de $\beta$-lg. Se probaron cantidades de $1 \mathrm{~g}, 0,5 \mathrm{~g}, 0,25 \mathrm{~g}$ y $0,125 \mathrm{~g}$ de $\beta$-lg.

Para obtener las películas con la vitamina adicionada se disolvieron $20 \mathrm{mg}$ de $\alpha$-tc en $0,5 \mathrm{~mL}$ de alcohol absoluto, luego se llevó a volumen de $5 \mathrm{~mL}$ con buffer Pi $20 \mathrm{mM} \mathrm{pH}$ 6,80 conteniendo disueltos $0,125 \mathrm{~g}$ de $\beta$-lg, y se completaron los $10 \mathrm{~mL}$ de sistema añadiendo un volumen de $5 \mathrm{~mL}$ de solución de AS 2 \% p/V en buffer Pi 20 mM pH 6,80 (Soazo, et al., 2015a), homogeneizando por agitación manual suave.

Las mezclas obtenidas se vertieron en placas de Petri de $5 \mathrm{~cm}$ de diámetro y, para evitar la acción del aire y la luz, estas se introdujeron dentro de una caja plástica cerrada con conductos de entrada y salida por los que se aplicó un flujo de nitrógeno. Por último, la caja plástica se colocó dentro de una estufa, donde se secaron las muestras durante $6 \mathrm{~h} \mathrm{a} 40^{\circ} \mathrm{C}$. Las películas obtenidas se guardaron en bolsas de polietileno cerradas al vacío y al abrigo de la luz en una cámara de control de humedad (Pharma SCT, Buenos Aires, Argentina) a 55\% de humedad y $25^{\circ} \mathrm{C}$ de temperatura hasta su utilización.

\section{Opacidad y color}

Se determinó la opacidad de las distintas películas siguiendo la metodología propuesta por (Siripatrawan y Harte, 2010). Se tomaron cinco muestras rectangulares $(10 \mathrm{~mm} \times 30 \mathrm{~mm})$ de diferentes partes de una película y se ubicaron en el lado interno de una celda de espectrofotómetro Jasco V-500 (Jasco International Co., Ltd., Tokyo, Japan). La absorbancia de luz de las muestras de películas fue medida a una longitud de onda de $600 \mathrm{~nm}\left(\mathrm{Abs}_{600}\right)$. La opacidad se calculó usando la ecuación:

Opacidad $=\mathrm{Abs}_{600} / l$

Donde $l$ es el espesor de la película en mm. Esta operación se repitió con tres películas diferentes de cada tipo. Para el estudio del color se determinaron los parámetros $L^{*}$ (claridad), $\mathrm{a}^{\star}$ (rojo-verde), $\mathrm{b}^{\star}$ (amarillo-azul) siguiendo el diseño descrito por Mendoza y Aguilera (2004) con algunas modificaciones (Soazo, et al., 2015b).

Los valores de $\Delta \mathrm{E}$ (diferencia de color total), definido como las diferencias entre los parámetros de color de la muestra y un blanco estándar, se calcularon siguiendo los trabajos de Yam y Papadakis (2004) y Soazo et al. (2015a). Todas las medidas se realizaron por quintuplicado.

\section{Estudio de la degradación \\ de $\alpha$-tc como función del tiempo de exposición al oxígeno del aire y radiación UV mediante HPLC}

Para estudiar la degradación del $\alpha$-tc por efecto de la acción del oxígeno y de la radiación lumínica en función del tiempo de exposición las distintas muestras fueron divididas en tres sistemas diferentes: A, B y C.

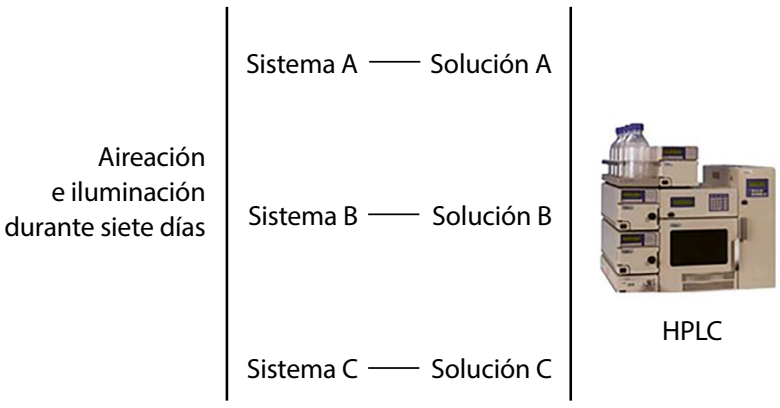

Figura 1. Representación esquemática de la experiencia realizada en el estudio de la degradación del $\alpha$-tc.

Sistema A: Solución de $\alpha$-tc $20 \mathrm{mg} / 100 \mathrm{~mL}$ en etanol absoluto (Solución A).

Sistema B: Solución de nanocomplejo a-tc $20 \mathrm{mg} / 100 \mathrm{~mL}$, $\beta$-lg 1,25\% p/V en Pi 20 mM pH 6,80 (Solución B).

Ambos sistemas fueron conservados en atmósfera de nitrógeno y oscuridad (para evitar la acción del oxígeno y la fotólisis) hasta su utilización.

Sistema C: Película de AS $\beta$-lg/ $\alpha$-tc. Se utilizaron siete películas diferentes.

Para el estudio del sistema $\mathrm{C}$ cada día se preparó una solución disolviendo una película en $100 \mathrm{~mL}$ de una mezcla 1:1 de buffer fosfato $20 \mathrm{mM} \mathrm{pH} \mathrm{6,80:} \mathrm{etanol} \mathrm{absoluto} \mathrm{(Solución} \mathrm{C).}$

El protocolo de trabajo se presenta en la Figura 1.

Los tres sistemas fueron expuestos durante siete días a la acción del oxígeno del aire ambiental y de una radiación lumínica (fluorescente blanco de 36 Vatios con un flujo luminoso $(F)$ de $3000 \mathrm{~lm}$ ) a una iluminancia $\left(E_{v}\right)$ de $200 \mathrm{~lx}$, medida con luxómetro Amprobe LM-100 (Amprobe Test Tools, Glottertel, Germany) resolución 0,1 lx. La temperatura se fijó en $25^{\circ} \mathrm{C}$.

\section{Cromatografía líquida de alta resolución}

Diariamente y durante siete días se le extrajo a cada una de las tres soluciones formadas el $\alpha$-tc, según el método propuesto por Liang et al. (2011). Cada muestra obtenida fue luego inyectada en un cromatógrafo HPLC Shimadzu LC-10 (Kyoto, Japan), anexado a una columna LC-18 $(25 \mathrm{~cm}$ $\mathrm{x} 4,6 \mathrm{~mm}$ ) SUPELCOSIL (Sigma-Aldrich, St. Louis, MO, USA): tamaño de partícula $5 \mu \mathrm{m}$, tamaño de poro 100 Å. Las condiciones cromatográficas fueron: detector $U V, \lambda=292 \mathrm{~nm}$; fase móvil isocrática, metanol absoluto; velocidad de flujo 1 $\mathrm{mL} / \mathrm{min}$; temperatura de la columna $45^{\circ} \mathrm{C}$. Las mediciones se realizaron por triplicado.

\section{Resultados y Discusión}

\section{Interacción de la $\beta$-lg con $\alpha$-tc}

\section{Medidas de turbidez de $\alpha$-tc a distintos valores de $\mathrm{pH}$}

En el Gráfico 1 se representan los valores de turbidez para los sistemas $\beta$-lg (nativa y desnaturalizada)/ $\alpha$-tc comparados con $\alpha$-tc sola (los resultados a $\mathrm{pH} \mathrm{3,00} \mathrm{y} \mathrm{6,80} \mathrm{fueron} \mathrm{similares,}$ razón por la cual se graficó la curva obtenida a $\mathrm{pH} 6,80$ ). La turbidez de estos sistemas es menor que la observada en las respectivas dispersiones sin proteína. Esto se debe a que 
en medio acuoso el $\alpha$-tc se uniría a la proteína formando un complejo soluble, hecho que podría tomarse como un indicador de la eficiencia de la proteína para vehiculizar un compuesto lipofílico.

A pH 3,00 el sistema formado presenta mayor turbidez que a $\mathrm{pH} 6,80$. Este comportamiento podría adjudicarse a la menor cantidad de sitios de fijación que expondría la proteína al estar principalmente como monómero. La proteína a $\mathrm{pH}$ 6,80 presenta una estructura compuesta por un $11 \%$ de monómeros y un $89 \%$ de dímeros, motivo por el cual expondría mayor cantidad de sitios de fijación (Moro, et al., 2011), e incluso también pueden aparecer otros sitios hidrofóbicos inespecíficos ubicados en la superficie proteica (Liang, et al., 2012).

Los complejos $\beta$-lg (desnaturalizada)/ $\alpha$-tc presentaron mayor turbidez que $\beta$-lg (nativa)/ $\alpha$-tc. Este hecho se debería a la pérdida de sitios de fijación cuando es desnaturalizada por calentamiento (Busti, et al., 2005), por lo cual se puede descartar al complejo $\beta$-lg (desnaturalizada)/ $\alpha$-tc a pH 6,80 como sistema de estudio.

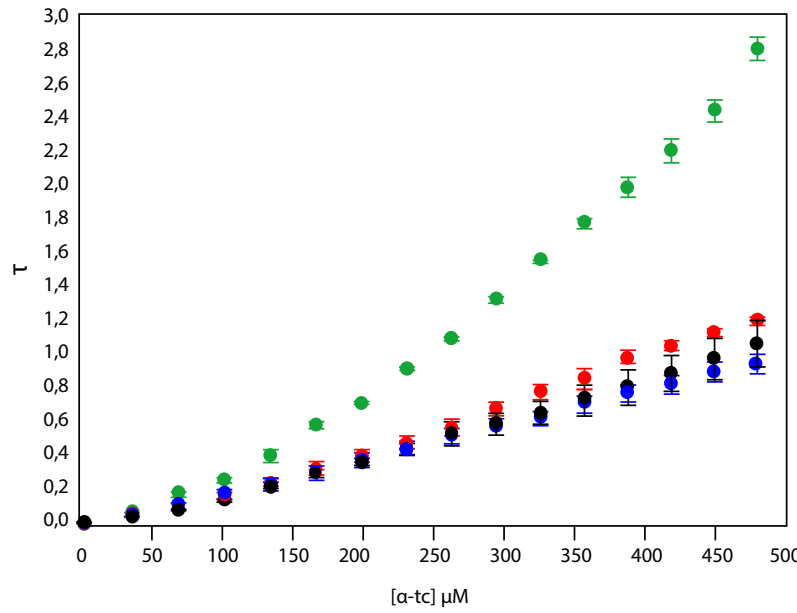

Gráfico 1. Turbidez $(\tau)$ de soluciones de $\alpha$-tc $(\bullet), \alpha$-tc $\operatorname{con} \beta$-lg (desnaturalizada) en buffer Pi $20 \mathrm{mM} \mathrm{pH} \mathrm{6,80( \bullet ),} \alpha$-tc con $\beta$-lg en buffer Pi $20 \mathrm{mM} \mathrm{pH} 6,80$ (•), $\alpha$-tc con $\beta$-lg en buffer Pi $20 \mathrm{mM} \mathrm{pH} \mathrm{3,0} \mathrm{( \bullet ).} \mathrm{Concentración} \mathrm{de} \mathrm{la} \mathrm{proteína} 20 \mu \mathrm{M}$.

\section{Obtención de películas de AS $\beta$-lg/ $\alpha$-tc}

La Figura 2 muestra las películas obtenidas para distintas relaciones proteína-alginato. Para valores de $1 \mathrm{~g}, 0,5 \mathrm{~g}, \mathrm{y}$ $0,25 \mathrm{~g}$ de $\beta$-lg resultaron quebradizas, mientras que la de $0,125 \mathrm{~g}$ de $\beta$-lg se mostró homogénea, maleable y traslúcida, características deseables para su posterior uso como vehículo de $\alpha$-tc. Esto puede deberse a que, si bien a pH 6,8 ambas especies tienen cargas netas negativas y entre ellas se generan fuerzas repulsivas electrostáticas que las mantienen en solución (Qomarudin, et al., 2015), la calidad de las películas formadas al secar dichas soluciones es dependiente de la masa de proteína utilizada para una determinada cantidad de AS.

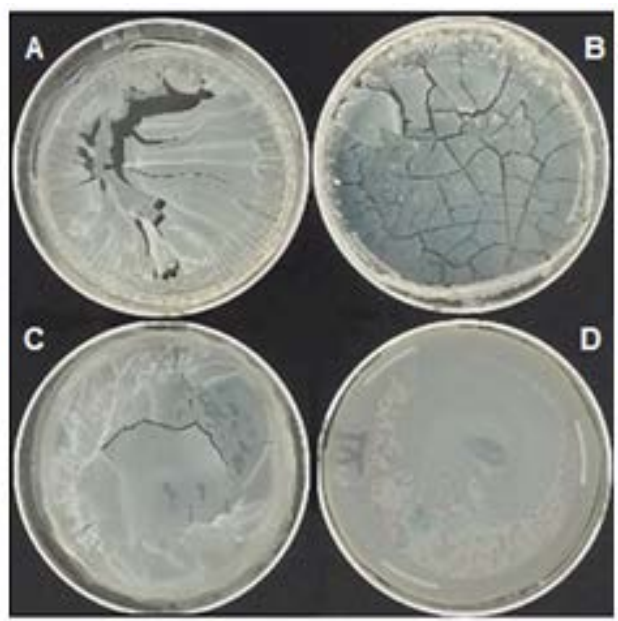

Figura 2. Películas de alginato $1 \% \mathrm{p} / \mathrm{V}$ en solución reguladora fosfato $20 \mathrm{mM}$ a pH 6,8 con: $\mathrm{A}: 10 \% \mathrm{p} / \mathrm{V}$, B: $5 \%(\mathrm{p} / \mathrm{v}), \mathrm{C}: 2,5 \%(\mathrm{p} / \mathrm{v}), \mathrm{D}: 1,25 \%(\mathrm{p} / \mathrm{v})$

Las películas AS $\beta-\lg / \alpha-t c$, con $20 \mathrm{mg}$ (por película) de $\alpha$-tc, correspondiente con la ingesta diaria máxima recomendada, no variaron su calidad, fueron homogéneas y maleables, y presentaron un espesor de entre 30 y $60 \mu \mathrm{m}$ (Figura 3 ).

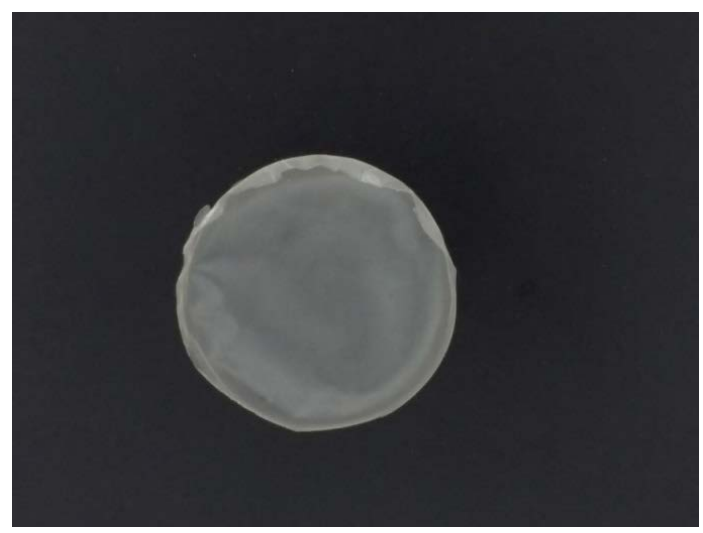

Figura 3. Película AS $\beta-\lg / \alpha$-tc, en solución reguladora fosfato $20 \mathrm{mM}$ a pH 6,8. Cantidad de alginato: $0,100 \mathrm{~g}$. Cantidad de $\beta$-lg: 0,125 g. Cantidad de $\alpha$-tc: $20 \mathrm{mg}$.

\section{Opacidad y color}

El estudio de opacidad y color de las películas se ve reflejado en la Tabla 1, donde se evidencia que el agregado de la

\begin{tabular}{|c|c|c|c|c|c|}
\hline Membrana & Opacidad & $\mathbf{L}^{*}$ & $\mathbf{a}^{*}$ & $\mathbf{b}^{*}$ & $\Delta \mathrm{E}$ \\
\hline AS $\sim \beta-\lg$ & $4,4 \pm 0,5$ & $64,6 \pm 1,5$ & $10,2 \pm 1,6$ & $38,6 \pm 2,2$ & $33,6 \pm 2,5$ \\
AS $\sim \beta-\lg / \alpha-\mathrm{tc}$ & $4,3 \pm 0,5$ & $63,4 \pm 1,8$ & $10,3 \pm 1,3$ & $38,0 \pm 1,7$ & $34.1 \pm 3,0$ \\
\hline
\end{tabular}

Tabla 1. Propiedades ópticas de las películas. 
vitamina, en forma de complejo con la proteína, no altera sus características ópticas.

\section{Estudio de la degradación de a-tocoferol}

En el Gráfico 2 se presentan las curvas de degradación de a-tc por efecto de la acción del oxígeno del aire e intensa radiación lumínica en función del tiempo de exposición.

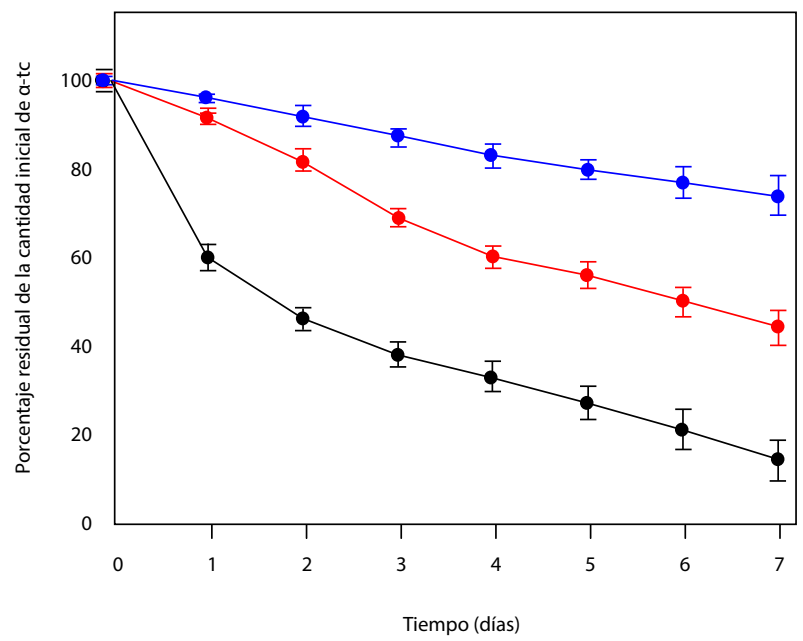

Gráfico 2. Degradación de $\alpha$-tc a distintos tiempos de almacenaje, solución de etanol $(\bullet)$, solución de $\beta$-lg/ $\alpha$-tc $(\bullet)$ y películas de AS $\beta$-lg/a-tc $(\bullet)$.

El análisis del Gráfico 2 muestra que al someter el $\alpha$-tc a condiciones oxidantes su estructura se va degradando.

$\mathrm{Al}$ séptimo día, la vitamina disuelta en alcohol mantiene intacto solamente un $14 \pm 4,6 \%$ de su estructura (curva en color negro).

La $\beta$-lg la protege, manteniendo intacto un $44 \pm 4,0 \%$ de su estructura, por la formación de los nanocomplejos solubles (curva en color rojo).

La muestra proveniente de la película mantiene un $74,5 \pm 4,5 \%$ de su estructura original intacta (curva color azul). Esto indica que la presencia de AS en la película aumenta el efecto protector que la $\beta$-lg ya ejerce al formar el complejo, posiblemente por una acción sinérgica con la proteína.

No se realizaron estudios de absorción de agua debido a que las películas no mostraron cambios macroscópicos en su calidad luego de estar expuestas al aire ambiental durante el tiempo de estudio.

\section{Conclusión}

Se formaron nanocomplejos por fijación de $\alpha$-tc a $\beta$-lg en sitios específicos e inespecíficos de su superficie a $\mathrm{pH} 6,80$. Las películas obtenidas permitieron incorporar el complejo $\beta$-lg/ $\alpha$-tc (respetando la concentración de $\alpha$-tc correspondiente a la ingesta máxima diaria), y se lograron estructuras homogéneas, traslúcidas y maleables, sin que el agregado de vitamina afecte sus propiedades. En cuanto a la estabilidad del $\alpha$-tc, las películas demostraron proteger su integridad ante la acción de agentes oxidantes. La aplicación de estas películas puede resultar útil para mantener la estructura de la vitamina conservada en el tiempo hasta su incorporación en alimentos o preparaciones farmacéuticas.

\section{Referencias}

Báez, G. D., Moro, A., Ballerini, G. A., Busti, P. A. y Delorenzi, N. J., 2011. Comparison between structural changes of heat-treated and transglutaminase cross-linked betalactoglobulin and their effects on foaming properties. En: Food Hydrocolloids, 25(7), pp.1758-1765.

Busti, P., Gatti, C. A. y Delorenzi, N. J., 2000. Some aspects of $\beta$-lactoglobulin structural properties in solution studied by fluorescence quenching. En: International Journal of Biological Macromolecules, 23(1998), pp.143-148.

Busti, P., Gatti, C. A. y Delorenzi, N. J., 2005. Thermal unfolding of bovine $\beta$-lactoglobulin studied by UV spectroscopy and fluorescence quenching. En: Food Research International, 38(5), pp.543-550.

de Kruif, C. G., Weinbreck, F. y de Vries, R., 2004. Complex coacervation of proteins and anionic polysaccharides. En: Current Opinion in Colloid \& Interface Science, 9(5), pp.340-349.

Delorenzi, N. J., 2005. Beta-lactoglobulin conformational changes studied by fluorescence quenching. En: Riley, Arthur, P., ed., 2005. Food research, safety and policies. New York: Nova Science Publishers. pp.169-183

Draget, K. I., 2009. Alginates. En: Glyn, O. Phillips, Williams, P. A. Handbook of hydrocolloids. 2a ed. London: Woodhead Publishing. pp.807-828

Fioramonti, S. A., Pérez, A. A., Aríngoli, E. E., Rubiolo, A. C. y Santiago, L. G., 2014. Food hydrocolloids design and characterization of soluble biopolymer complexes produced by electrostatic self-assembly of a whey protein isolate and sodium alginate. En: Food Hydrocolloids, 35, pp.129-136.

Giroux, H. J. y Britten, M., 2011. Encapsulation of hydrophobic aroma in whey protein nanoparticles. En: Journal of Microencapsulation, 28(5), pp.337-343.

Jones, O. G., Decker, E. A. y McClements, D. J., 2009. Formation of biopolymer particles by thermal treatment of $\beta$-lactoglobulin-pectin complexes. En: Food Hydrocolloids, 23(5), pp.1312-1321.

Liang, L. y Subirade, M., 2012. Study of the acid and thermal stability of $\beta$-lactoglobulin-ligand complexes using fluorescence quenching. En: Food Chemistry, 132(4), pp.2023-2029.

Liang, L., Tremblay-Hébert, V. y Subirade, M., 2011. Characterisation of the b-lactoglobulin/a-tocopherol complex and its impact on a-tocopherol stability. En: Food Chemistry, 126(3), pp.821-826.

Livney, Y. D., 2010. Milk proteins as vehicles for bioactives. En: Current Opinion in Colloid \& Interface Science, 15(1), pp.73-83.

Mendoza, F. y Aguilera, J. M., 2004. Application of image analysis for classification of ripening bananas. En: Journal of Food Science, 69(9), pp.474-477.

Moro, A., Báez, G. D., Busti, P. A., Ballerini, G. A. y Delorenzi, N. J., 2011. Effects of heat-treated $\beta$-lactoglobulin and its aggregates on foaming properties. En: Food Hydrocolloids, 25(5), pp.1009-1015.

Moro, A., Gatti, C. y Delorenzi, N., 2001. Hydrophobicity of whey protein concentrates measured by fluorescence quenching and its relation with surface functional 
properties. En: Journal of Agricultural and Food Chemistry, 49(10), pp.4784-4789.

Mousavi, S. H.-A., Bordbar, A.-K. y Haertlé, T., 2008. Changes in structure and in interactions of heat-treated bovine beta-lactoglobulin. En: Protein and Peptide Letters, 15(8), pp.818-825.

National Institute of Health, Office of Dietary Supplements, 2016. Vitamina E: hoja informativa para consumidores [En línea]. Besthesda: NIH. [Consulta: 13/2/2017]. Disponible en: https://ods.od.nih.gov/factsheets/ VitaminE-DatosEnEspanol/

Pereira, R., Carvalho, A., Vaz, D. C., Gil, M. H., Mendes, A. y Bártolo, P., 2013. Development of novel alginate based hydrogel films for wound healing applications. En: International Journal of Biological Macromolecules, 52, pp.221-230.

Qomarudin, Q., Orbell, J., Ramchandran, L., Gray, S. R., Stewart, M. B. y Vasiljevic, T., 2015. Properties of beta-lactoglobulin / alginate mixtures as a function of component ratio, $\mathrm{pH}$ and applied shear. En: Food Research International, 71, pp.23-31.

Relkin, P. y Shukat, R., 2012. Food protein aggregates as vitamin-matrix carriers: Impact of processing conditions. En: Food Chemistry, 134(4), pp.2141-2148.

Relkin, P., Shukat, R. y Moulin, G., 2014. Encapsulation of labile compounds in heat- and high-pressure treated protein and lipid nanoparticles. En: Food Research International, 63, pp.9-15.

Rhim, J.-W., 2004. Physical and mechanical properties of water resistant sodium alginate films. En: $L W T$ - Food Science and Technology, 37(3), pp.323-330.
Romero, G. C. A., Malo, A. L. y Palou, E., 2013. Propiedades del alginato y aplicaciones en alimentos. En: Temas Selectos de Ingeniería de Alimentos, 7(1), pp.87-96.

Ron, N., Zimet, P., Bargarum, J. y Livney, Y. D., 2010. Betalactoglobulin-polysaccharide complexes as nanovehicles for hydrophobic nutraceuticals in non-fat foods and clear beverages. En: International Dairy Journal, 20(10), pp.686-693.

Siripatrawan, U. y Harte, B. R., 2010. Physical properties and antioxidant activity of an active film from chitosan incorporated with green tea extract. En: Food Hydrocolloids, 24, pp.770-775.

Soazo, M., Báez, G., Barboza, A., Busti, P., Rubiolo, A., Verdini, R. y Delorenzi, N., 2015a. Heat treatment of calcium alginate films obtained by ultrasonic atomizing: physicochemical characterization. En: Food Research International, 51, pp.193-199.

Soazo, M., Pérez, L., Rubiolo, A. y Verdini, R., $2015 b$. Prefreezing application of whey proteinbased edible coating to maintain quality attributes of strawberries. En: Intl J Food Sci Tech, 50(3), pp.605-611.

Tavares, G. M., Croguennec, T., Carvalho, A. F. y Bouhallab, S., 2014. Milk proteins as encapsulation devices and delivery vehicles: Applications and trends. En: Trends in Food Science \& Technology, 37(1), pp.5-20.

Yam, K. L. y Papadakis, S. E., 2004. A simple digital imaging method for measuring and analyzing color of food surfaces. En: Journal of Food Engineering, 61, pp.137-142.

Zimet, P. y Livney, Y. D., 2009. Beta-lactoglobulin and its nanocomplexes with pectin as vehicles for $\omega-3$ polyunsaturated fatty acids. En: Food Hydrocolloids, 23(4), pp.1120-1126. 